\title{
PSICODRAMA COMO ESTRATÉGIA PEDAGÓGICA: VIVÊNCIAS NO ENSINO DE GRADUAÇÃO NA ÁREA DE SAÚDE DA MULHER
}

\author{
Normélia Maria Freire Diniz* \\ Regina Lúcia Mendonça Lopes** \\ Mariza Silva Almeida*** \\ Solange Maria dos Anjos Gesteira**** \\ Jeane Freitas de Oliveira*****
}

DINIZ, N.M.F.; LOPES, R.L.M.; ALMEIDA, M.S.; GESTEIRA, S.M.dos A.; OLIVEIRA, J.F.de. Psicodrama como estratégia pedagógica: vivências no ensino de graduação na área de saúde da mulher. Rev.Latino-am.enfermagem, Ribeirão Preto, v. 8, n. 4, p. 88-94, agosto 2000.

A partir de uma discussão do Grupo de Estudos sobre Saúde da Mulher - GEM, o psicodrama tem sido utilizado como estratégia pedagógica para desenvolver o tema Condição Feminina e Saúde da Mulher. Depoimentos individuais, verbalizados e escritos, e histórias construídas na "vivência grupal", foram analisados sob a perspectiva de gênero. A dinâmica vem facilitando o relacionamento e o auto-conhecimento, possibilitando a emergência de situações do cotidiano. A reflexão entre o vivido e o teórico tem permitido a visibilidade da inserção feminina no espaço público e privado e criado situações para a construção de conceitos.

UNITERMOS: educação em saúde, psicodrama, saúde da mulher, condições sociais

\section{INTRODUÇÃO}

Percebe-se que a mulher ainda não é vista em sua integralidade, quando a prestação de serviço está pautada no modelo estrutural funcionalista, numa visão biológica, que não adota métodos participativos que lhe permitam ser sujeito, no que diz respeito à sua saúde. Dentre as diretrizes do Programa de Assistência Integral à Saúde da Mulher (PAISM), estabelecidas em 1983, são recomendadas práticas educativas que permeiem todas as ações desenvolvidas. Busca-se, portanto, assegurar a apropriação pela clientela dos conhecimentos necessários a um maior controle sobre sua saúde, uma nova postura $\mathrm{e}$, conseqüentemente, uma nova abordagem da equipe de saúde, no desenvolvimento dos programas de capacitação de recursos humanos ${ }^{2}$.

Desde a década passada, a capacitação através de oficinas tem sido identificada como componente decisivo para assegurar que organizações governamentais ou não governamentais (ONGs), que abordam temáticas relacionadas à mulher, integrem o enfoque de planejamento de gênero em seu trabalho. Novos enfoques, cursos e oficinas de trabalho têm se desenvolvido e multiplicado, na medida em que as instituições e os indivíduos buscam cobrir essas necessidades.

O Grupo de Estudos sobre Saúde da Mulher GEM, da Escola de Enfermagem da Universidade Federal da Bahia, desde a sua criação (1988) tem introduzido novos conteúdos tais como: gênero, sexualidade, planejamento familiar, aborto, doenças sexualmente transmissíveis, direitos reprodutivos, cidadania feminina, violência e relações de poder. Estes conteúdos, que fazem parte dos programas de disciplinas da graduação e da pós-graduação, são desenvolvidos a partir de oficinas de práticas educativas, estratégias essas já aplicadas pelo movimento feminista, quando do treinamento de profissionais sobre a questão de gênero. Nesse sentido, modificou-se a dinâmica dos trabalhos educativos, até então existentes, caracterizados pela transmissão de conhecimento de forma vertical, onde se "pensa que quanto mais se dá mais se sabe" (FREIRE ${ }^{3}$, p. 38) para uma abordagem participativa contemplada no âmbito do PAISM através de oficinas, visando o fortalecimento da mulher como sujeito de sua saúde.

\footnotetext{
* Doutora em Enfermagem-EPM. Docente da EEUFBA. Coordenadora do Grupo de Estudos sobre Saúde da Mulher GEM ** Doutora em Enfermagem-UFRJ. Docente da EEUFBA. Pesquisadora do GEM

*** Mestra em Enfermagem-UFBA. Docente da EEUFBA. Pesquisadora do GEM

$* * * *$ Mestra em Enfermagem-EPM. Docente da EEUFBA. Pesquisadora do GEM

***** Mestranda em Enfermagem-UFBA. Docente da EEUFBA. Pesquisadora do GEM
} 
O objetivo básico do PAISM de diminuir a morbimortalidade feminina permeia, também, a noção da condição feminina, com as questões relativas à sexualidade, ao trabalho e à igualdade social, desenvolvidas nas diferentes fases de implantação, quando efetivamente concretizadas, através da municipalização dos Serviços de Saúde, obedecendo aos princípios preconizados pelo Sistema Único de Saúde (SUS).

Antes de pensar em uma capacitação de gênero, se requer a escolha de uma estratégia metodológica, pois tal capacitação é considerada como uma poderosa metodologia de transformação, através da qual reflete-se sobre novas atitudes, conhecimentos e habilidades.

Diferentes cursos de capacitação têm sido realizados, permitindo a identificação de três metodologias: análise de gênero, planejamento de gênero e dinâmicas de gênero. Tais experiências foram referendadas na Conferência em Bergen - Noruega (1991), onde os participantes chegaram ao consenso da existência desses três enfoques supra citados, entendendo contudo, que os mesmos não abarcam todas as metodologias.

Sabe-se que, os objetivos da capacitação variam desde uma conscientização generalizada sobre as questões de gênero, até a necessidade específica de uma qualificação técnica. Apesar dos cursos de capacitação utilizarem mais de um objetivo, é necessário, sem dúvida, ter clareza quanto a sua utilização.

Entre os objetivos propostos têm-se: sensibilizar para o tema "mulher e desenvolvimento" e "gênero e desenvolvimento"; capacitar os sujeitos para análise e diagnóstico de gênero; garantir a aplicação na prática dos conhecimentos construído no decorrer do curso; e capacitar, através dos fatores motivacionais, com vistas a estimular os participantes.

Apesar da capacitação em dinâmica de gênero contemplar objetivos múltiplos, a questão da "subordinação" ainda gera polêmica, pelo fato dos profissionais terem percepções e valorizações diferentes. A premissa básica das feministas de que "o pessoal é político", supõe que as oficinas com esse tema sejam altamente contraditórias, para aqueles que não estão de acordo com a existência da subordinação da mulher em relação ao homem. Sendo assim, tem-se como meta a redução de tensões, enfatizando o pressuposto básico de que a capacitação para um planejamento de gênero se destina ao "profissional"

A ênfase no profissional supõe, por razões estratégicas, uma consciência a priori da importância do tema e visa a qualificação técnica necessária para melhorar a competência profissional. Isto permite aos participantes aceitar, sem hostilidades, a identificação do tema de gênero; a avaliação da necessidade de gênero; a matriz da política de gênero e desenvolvimento; e a mulher e desenvolvimento.

Tem-se clareza que, a distinção entre as necessidades práticas e as estratégias de capacitação em gênero, é um instrumento crítico que ajuda os participantes a reconhecer a interrelação entre o político, o profissional e o pessoal, dando ênfase que, a diluição de tensões é a parte básica dessa estratégia. Ao desmistificar também a difundida crença de que todas as intervenções para ajudar a mulher são feministas, permite aos participantes a apropriação de uma outra forma de ver as intervenções consideradas inapropriadas. Sem dúvida, também permite um começo de um reexame da sua postura pessoal e política, sobre o tema da subordinação da mulher.

Escolhemos a capacitação em dinâmica de gênero por ter em sua base social mulheres e profissionais das ONGs. Este enfoque, que tem sido bem documentado ao longo do tempo, compreende várias metodologias independentes, intensamente participativas, inovadoras e flexíveis, desenhadas para capacitar a mulher para reconhecer, analisar e abordar aspectos de gênero em sua comunidade.

Segundo afirmativas de autores citados por MOSER $^{7}$, as habilidades interpessoais que comprometem "no sólo el cuerpo, sino el corazón" (Aklilu, 1991) conduzem a técnica básica de capacitação, que para Theresa Balayon (1991),

"dinámicas de género es un seminario concientizador que discute cuestiones relacionadas con la naturaleza, los orígenes, la extensión, los efectos, y las alternativas del prejuicio de género...[para] identificar el prejuicio de género en el hogar, en el trabajo, $y$ en la sociedad en general; interpretar algunas experiencias a la luz de valores y principios feministas; reconciliar diversos puntos de vista del movimiento de la mujer; corregir normas sexistas de pensamiento, lenguage y comportamiento; e integrar valores de la equidad de género al proprio plan de acción personal y profesional".

Como o termo sugere, as dinâmicas de gênero estão baseadas, sobretudo, em atividades interativas, dinâmicas interpessoais e jogos de papéis. Em alguns contextos, as estratégias adicionais têm incluído o uso do teatro popular, como um trabalho de Sistrem, na Jamaica $\left(\right.$ MOSER $\left.^{7}\right)$.

\section{OBJETIVO}

Dando continuidade a proposta educativa do PAISM, a partir da vivência de alunos e professoras de 
Enfermagem do Curso de Graduação, na Disciplina Enfermagem na Atenção à Saúde da Mulher, realizamos este estudo com o objetivo de desenvolver a discussão da temática Condição Feminina e Saúde da Mulher. Neste intuito, o artigo tem como proposta divulgar a experiência docente de apropriação do psicodrama como estratégia pedagógica no desenvolvimento de questões relativas à saúde da mulher.

\section{TRAJETÓRIA DO CAMINHO METODOLÓGICO}

A metodologia é o determinante mais crítico do conteúdo da capacitação, por definir os detalhes mais específicos relacionados ao tema, como: a programação e o formato das oficinas; a estrutura do conteúdo de cada sessão; e os recursos necessários.

Se o objetivo é desenvolver habilidade de gênero, os programas de capacitação podem ser formulados de forma mais ampla. Se é o trabalho de qualificação, à prática de planejamento deve-se incorporar os procedimentos de trabalho das organizações. A capacitação, portanto, deve ser elaborada para cobrir as necessidades dos diferentes grupos organizacionais.

Dado ao enfoque particular da metodologia, o planejamento de gênero enfatiza a importância do uso de materiais corrente nas organizações, devendo estes ser construídos para cada grupo específico, observandose a prioridade ditada pelo cotidiano, fundamentados em projetos e programas.

Considerando ser a população alvo constituída de alunas(os) do $7^{\circ}$ período do Curso de Graduação em Enfermagem, matriculadas na disciplina Enfermagem na Atenção à Saúde da Mulher, a estratégia pedagógica embasou-se no referencial teórico de psicodrama, a seguir detalhado, e que foi apropriado para a área da enfermagem sob a condução de um membro da equipe docente $* * * * * *$ com formação específica.

\section{A operacionalização de uma capacitação}

A capacitação deve estar pautada, portanto, num planejamento estratégico, identificando o grupo que realmente necessita recebê-la, tendo em vista o êxito.

A dimensão do grupo também depende da metodologia da capacitação. A experiência de capacitação em planejamento tem demonstrado que, um grupo de 12 a 15 pessoas é um tamanho ideal. Dada a sua metodologia, altamente participativa, com um maior quantitativo haverá menos espaço para participação, permitindo que os menos interessados se sintam à parte. Num grupo pequeno, há falta de diversidade de experiência pode tornar a capacitação menos interessante. Sem dúvida, essa questão está também relacionada com a duração da capacitação, tendo-se evidenciado na prática, que quanto maior for o nível dos profissionais mais ocupados eles estão. O tempo gasto numa capacitação, dependerá da qualificação e da necessidade do grupo. Em média, sua duração deverá ser de 1 dia, sendo que, a prática tem demonstrado ser a duração de 3 dias ideal para pessoal de nível superior.

A capacitação é um instrumento mínimo, porém importante para assegurar que a instituição incremente um número de generalista com consciência de gênero, podendo ser definida como expansão e consolidação da qualificação técnica, para levar conhecimentos à prática. Depende de diversas técnicas pedagógicas como: práticas de relaxamento, discussões de pequenos grupos e sessões de jogos de idéias.

Quando se necessita identificar um profissional para realizar uma capacitação em gênero, se assume que um planificador ou um acadêmico, com conhecimento de gênero, pode habilitar-se.

\section{Como avaliar a capacitação: procedimentos de avaliação}

Ao longo do tempo, têm ocorrido poucas iniciativas sistemáticas de avaliar quantitativamente a capacitação de gênero. Os questionários estimam os "coeficientes de felicidade", o nível de satisfação com a capacitação, mas não identificam seu impacto nas práticas de trabalho. O impacto pode ser monitorado em termos da cooperação resultante de uma prática de trabalho, entre as instituições e os indivíduos. No entanto, existe um problema identificado por Cristian Aid, ressaltado por $\mathrm{MOSER}^{7}$, que é a distinção entre o espírito da linguagem retórica e o implementado na prática.

Anderson citado por $\operatorname{MOSER}^{7}$ afirma que, o impacto da capacitação sobre os participantes pode ser identificado em termos de mudança de atitudes, maiores qualificações, conhecimento e mudança de conduta. Estes últimos são mais difíceis de avaliar, do que as mudanças institucionais.

Entre os impactos externos distingüidos por esse autor têm-se o "desenvolvimento melhorado" e a "igualdade incrementada", cujo principal objetivo é enfatizar a importância da análise de gênero, como estratégia para decidir como usar os recursos de

****** Professora Doutora Normélia Maria Freire Diniz. Companhia de Teatro Espontâneo de Tietê - São Paulo. Curso de Formação em Psicodrama com carga horária de 360 horas 
desenvolvimento e, mais efetivamente, para alcançar as metas e a produção econômica e, em seguida, poder ser usado para avaliar os enfoques baseados na " hipótese da eqüidade". Esta última, se centra no gênero, em termo de sua influência para assegurar os benefícios sociais e econômicos do desenvolvimento e, por isso, a igualdade entre homens e mulheres, sendo que, qualquer avaliação da efetividade da capacitação depende do enfoque assumido.

Vale ressaltar, que o modelo de avaliação proposto por Anderson, ainda não foi submetido à prova. No entanto, a partir de quase uma década de experiência, as provas qualitativas têm demonstrado, claramente, que a capacitação de gênero institucionalizada, desempenha um rol decisivo em um lento processo de mudança, não sendo um fim em si mesmo, mas um meio para as mudanças.

Sem dúvida, a capacitação por conta própria não pode resolver o problema da subordinação da mulher, podendo somente ser desafiada mediante uma intervenção política. Em última análise, o planejamento de gênero necessita de uma agenda política.

\section{A escolha do psicodrama}

Utilizamos o método Educacional Psicodramático, proposto por ROMAÑA ${ }^{8}$, para a realização da prática educativa, enfatizando o estudo das relações de gênero. Este método pode ser utilizado para situações especiais, onde o conhecimento é decorrente de uma aprendizagem simultânea à experiência de vida, pois segundo a autora "sabemos porque vivemos $\mathrm{e}$ experimentamos" (p.51). O psicodrama, como teoria que fundamenta uma prática de ação, tem na espontaneidade o seu conceito mais importante.

No psicodrama, a ação espontânea favorece o desempenho de papéis e de articulação de respostas, conhecidas ou até padronizadas, como se fosse a primeira vez que as estivéssemos realizando. Além disso, a partir da originalidade, possibilita desenvolver a capacidade de formular uma resposta semelhante, porém com uma marca própria. Finalmente, temos na criatividade, a capacidade de formular uma resposta inédita, até o momento, dentro do universo de referência de cada participante ou grupo. ROMAÑA ${ }^{8}$ ressalta que, " $a$ resposta criativa seria como por um novo ser no mundo fisico ou cultural"'(p.51).

Vale ressaltar, que a temática gênero, tendo como técnica de desenvolvimento o psicodrama, já vem sendo trabalhada por um grupo em Córdoba - Argentina, coordenado por Ana Maria Garavelli, tendo sido a experiência apresentada no $9^{\circ}$ Congresso Brasileiro de Psicodrama, em São Paulo ${ }^{4}$.

Como técnicas psicodramáticas, utilizamos em nossa experiência de capacitação, recursos sugerido por ROMAÑA ${ }^{8}$ quais sejam: a inversão ou troca de papéis; o solilóquio (falar como se estivesse pensando alto); a interpolação de resistências (desestruturação da cena com a inserção de um fato novo), além de depoimentos individuais verbalizados escritos e dramatizações construídos na vivência grupal, desenvolvida através de psicodrama e de trabalhos participativos, dentro de uma carga horária de 20 horas. Como suporte, usamos referencial teórico sobre o tema em estudo, conforme o detalhado a seguir:

\begin{tabular}{|c|c|c|}
\hline ENCONTRO & $\begin{array}{c}\text { A Condição } \\
\text { Feminina }\end{array}$ & $\begin{array}{l}\text { ESTRATÉGIA } \\
\text { FACILITAD ORA } \\
\text { - psico drama com história } \\
\text { de mulheres } \\
\text { - leitura do texto "Transição } \\
\text { de Gênero: condição } \\
\text { feminina na socie dade } \\
\text { atual" de Karen Giffin }\end{array}$ \\
\hline $2^{\circ}$ & $\begin{array}{l}\text { A Mulher na } \\
\text { Sociedade }\end{array}$ & $\begin{array}{l}\text { - trabalho de colagem em } \\
\text { pequenos grupos } \\
\text { - apresentação e discussão } \\
\text { com grande grupo }\end{array}$ \\
\hline $3^{\circ}$ & Mulher e Poder & $\begin{array}{l}\text { - leitura dos capítulos } 1,2 \text { e } \\
3 \text { da obra "O Poder do } \\
\text { Macho" de Heleieth } \\
\text { Saffioti } \\
\text { - psicodrama }\end{array}$ \\
\hline $4^{\circ}$ & Gênero e Saúde & $\begin{array}{l}\text { - leitura do livro "A Mulher } \\
\text { face à Saúde e ao } \\
\text { Desenvolvimento" de } \\
\text { Rebecca de los Rios e Elsa } \\
\text { Gómez } \\
\text { - psicodrama }\end{array}$ \\
\hline $5^{\circ}$ & $\begin{array}{c}\text { A Assistência } \\
\text { de Saúde à } \\
\text { Mulher }\end{array}$ & $\begin{array}{l}\text { - leitura do capítulo O } \\
\text { Paradigma Emergente do } \\
\text { livro "Um Discurso sobre } \\
\text { as Ciências" de Boaventura } \\
\text { de Souza Santos" } \\
\text { - leitura da obra "A Crise } \\
\text { dos Paradigmas e a } \\
\text { Educação" de Zaia } \\
\text { Brandão la }\end{array}$ \\
\hline
\end{tabular}

Figura 1 - Quadro do programa das oficinas de capacitação para a sensibilização do conceito de gênero 
DESCRIÇÃO DOS PROCEDIMENTOS DE ENSINO

\section{Tentando retomar o psicodrama}

A grande sala ampla, ventilada e pouco iluminada, possuía uma magia toda especial. Ao lado de uma música relaxante, de onde se ouviam sons agradáveis, destacando-se o canto dos pássaros e o barulho das ondas chegando à praia, estava a emoção das professoras, aliada à ansiedade e à curiosidade das(os) alunas(os) pelo trabalho até então desconhecido. Iniciamos nosso aquecimento, após breve apresentação e explicação do significado da atividade proposta, do programa e da dinâmica, tendo como temática a Condição Feminina e Saúde da Mulher buscando a história da mulher no cotidiano, com o emprego da técnica do psicodrama.

Solicitamos que as(os) alunas(os) se concentrassem no assunto proposto, dando continuidade com as técnicas de relaxamento corporal. Nos colocamos em círculo, todos descalços, pois o carpete do piso nos deixava bem confortável, mantendo o fundo musical durante todo o trabalho de aquecimento. O papel de diretora foi representado por uma professora com formação em psicodrama. Em seguida, a diretora pediu que os elementos do grupo expressassem, de modo expontâneo, seus sentimentos, imagens e cenas que pudessem conduzir à pistas para a escolha da(o) protagonista.

Emergiram cinco situações do cotidiano, sendo sumariamente dramatizadas para que, em seguida, o grupo elegesse a cena a ser apresentada sob a forma de dramatização. O protagonista é o porta voz do drama; o grupo acompanha, confere, valida ou não as emoções pessoais envolvidas na encenação; os ego-auxiliares desenvolvem o papel de ator, cujo ingresso deve se dar na cena, como participante ativo do enredo. Estes foram escolhidas(os) pela (o) protagonista, à medida que a cena ia se desenvolvendo. O palco foi delimitado pela diretora, ficando a platéia, sentada em círculo ao redor deste.

\section{Encenação}

Cena 1 - Inicialmente, a história teve como enredo a vida de um casal, denominado por Severino e Maria, que possuía três filhas. A mãe não exercia atividades fora do lar, e somente Severino trabalhava no espaço público e assumia todas as despesas da casa. Devido ao descompromisso no trabalho, associado ao alcoolismo, foi demitido. A partir de então, a situação tomou outro rumo. Congelou-se a cena (interrupção da cena, enquanto a diretora fora da cena discute com o protagonista).

Mudou-se o cenário anterior. A diretora questionou de que forma o protagonista daria continuidade a essa história. Maria, a protagonista, respondeu que teria que procurar emprego para manutenção da casa. Mudou-se o cenário.

Cena 2 - Uma amiga informou a Maria sobre a existência de uma vaga no escritório de advocacia do Dr. Aníbal. Ao chegar no escritório, Maria percebeu imediatamente a situação delicada em que se encontrava, pois o patrão começou a assediá-la, deixando-a bastante insegura e nervosa, e esta não sabia o que fazer. Tinha apenas a certeza de que o sustento das suas filhas dependeria desse emprego.

O fato de sua esposa estar trabalhando fora, contribuiu para aumentar o ciúme de Severino, que a cada dia aumentava seu estado de embriaguez. Ameaçava despedir a empregada e exigia que Maria abandonasse o emprego, pois era conhecedor do comportamento desse advogado.

Maria se desesperou, pediu demissão, voltou para a casa e chorou ao lado das filhas, sendo acalmada pela empregada, que se dispôs a trabalhar e a receber o pagamento quando a situação melhorasse. Cena congelada. A diretora novamente solicitou $\mathrm{a}(\mathrm{o})$ atriz(ator) que definisse e continuasse a história.

Cena 3 - Os egos-auxiliares decidiram pela demissão da empregada, o abandono de Severino e pela ida de Maria e filhas para a casa de seus pais.

A diretora, congelou a cena e perguntou de que forma esta terminaria. Fez uma interpolação, solicitando a construção da cena do jeito que elas(es) imaginassem ser possível, buscando estimular a construção da fantasia . Apesar de verbalizarem que Maria poderia procurar a Delegacia da Mulher, para o registro queixa de assédio sexual, essa opção não foi a de escolha. A protagonista decidiu manter o final da história do modo anterior. Encerradas as dramatizações, a diretora solicitou que se desfizesse o palco, dando início a outra etapa do trabalho.

Foi solicitado aos participantes que compartilhassem com a protagonista, sentimentos experimentados durante o espaço/momento da dramatização, os momentos vividos e lembrados de sua própria vida (referencial histórico), sem ter a necessidade de se referir a uma cena memorizada.

Todas(os) ficaram em silêncio, tomadas(os) de emoção, expressando-se com histórias de suas vidas e se identificando como algum personagem. $\mathrm{O}$ resultado foi surpreendente: alguns choraram, compartilharam situações vivificadas, e até demonstraram sentimento de revolta com determinado personagem. Não foram permitidos comentários muito extensos podendo-se "mesmo prescindir deles" (ROMAÑA , p. 65).

Terminado esse compartilhamento, foi iniciada a discussão, buscando-se uma interação do contexto grupal com o coletivo. Assim, foram reconstruídas cenas sobre vidas de mulheres, que juntamente com os textos 
de apoio, serviram de base para iniciar a discussão e reflexão sobre a temática em estudo.

\section{O olhar dos(as) discentes}

Este etapa do trabalho não ofereceu dificuldades e substituiu os comentários tradicionais mais voltados para o "eu acho...", direcionando a atenção para o resgate das categorias mais objetivas. Esse resgate foi obtido através de depoimentos verbais e escritos, os quais destacamos dois aspectos analisados sob a perspectiva de gênero.

Quanto a VALORIZAÇÃO DO PROCESSO

GRUPAL, questionamos se teria sido essa atividade significativa ${ }^{* * * * * * *}$ e obtivemos vários depoimentos, afirmando ter sido esse trabalho "muito gratificante e produtivo"********. A valorização está presente em alguns depoimentos como: "Uma maneira de dinamizar e incluir novas formas didáticas..." ; "Gostei muito do psicodrama e de como foi discutido o texto, após a leitura"********. Além disto, “... contribuiu para conhecimento e integração do grupo, já que nessas práticas constroem-se conceitos e idéias novas"********. Outra aluna considerou que essa atividade "desenvolve o raciocínio e a capacidade que o aluno tem e que, às vezes, fica escondido dentro do seu próprio "eu”********.

Essa identificação foi importante, levando a alguns componentes do grupo em apreço, solicitar que essa atividade se mantivesse em outros momentos.

Identificamos como outro aspecto $\mathbf{O}$ PROCESSO DE MUDANÇA. Segundo os depoimentos podemos identificar a possibilidade de reflexão, pois como afirmou uma aluna " houve crescimento $e$ transformação por parte de cada um de nós (mulheres e homens) da turma ... nossa visão inclusive com estímulo à percepção, análise e crítica ... o que foi proporcionado pelas colagens, leituras e psicodrama"********. Apesar da aluna afirmar que houve mudanças, a mesma demonstrou insegurança relativa às possíveis mudanças e a quem caberá fazê-las.

Reafirmamos a importância da escolha de textos críticos sobre a temática em questão, que possam conduzir o alunado ao entendimento de outras visões da construção do conhecimento.

Outro depoimento em destaque, refere-se a oportunidade de "construir conceitos através de vivências aqui apresentadas ... e até onde minha teoria condiz com a minha prática? ... já que pertenço a um grupo que luta para ocupar seu espaço ... se eu realmente tenho essa visão de gênero, como posso colaborar para o avanço dessa questão? ’*********. Como podemos ver, a aluna comunga com a preocupação de Cristian Aid citado anteriormente, que afirma que o discurso teórico não pode estar dissociado da atuação prática. Isso reafirma o componente biologicista, que vem se mantendo nos dias atuais, e reforça a necessidade de mudança nas práticas pedagógicas, mas também a necessidade da expansão da capacitação de gênero não só no meio acadêmico, como também nos demais serviços.

\section{CONSIDERAÇÕES FINAIS}

Deve-se ficar claro, portanto, que as questões relacionadas à mulher não podem estar isoladas do contexto sócio-cultural, econômico e político no qual ela está inserida. Obviamente, o pressuposto básico desse trabalho contempla a discussão sobre a condição feminina e a reflexão acerca da saúde da mulher.

Quando assumimos, enquanto disciplina e Grupo de Estudos sobre a Saúde da Mulher, a luta por melhoria da condição feminina e pela igualdade entre homens e mulheres, a capacitação em dinâmica de gênero por nós trabalhada, busca conduzir, de forma mais rápida e eficaz, o alcance desses objetivos. A sensibilização do alunado tem como meta final, desenvolver o espírito de eqüidade e de igualdade de gênero entre homens e mulheres e construir o conhecimento sobre a temática em questão. Consideramos que esses objetivos foram alcançados, a medida que as(os) alunas(os) expressaram que houve crescimento e transformação em cada um de nós******** e preocupação com a dissociação entre 0 conhecimento teórico sobre as questões de gênero e a realidade encontrada no campo de prática.

******* A significação é aquilo que relaciona os aspectos afetivos como os cognitivos e conceituais da aprendizagem. Uma maior articulação entre o mundo afetivo e os métodos educativos reduzirá a desarmonia entre aprendizagem e comportamento. Afetividade não é só sentimento ou emoção intensos, é antes de mais nada uma expressão das forças básicas que direcionam e norteiam o comportamento. Os impulsos mais profundos que mobilizam o comportamento surgem dessas forças (Weinstein e Fantini. In: Romaña ${ }^{8}$, p. 72)

******** Depoimentos de alunas(os) que participaram do psicodrama 


\section{PSYCHODRAMA AS A PEDAGOGICAL STRATEGY: EXPERIENCES IN UNDERGRADUATION TEACHING IN THE FIELD OF WOMEN'S HEALTH}

As the result from a discussion by the Grupo de Estudos sobre Saude da Mulher-GEM (Group of Studies on Women's Health), psychodrama has been used as a pedagogical strategy to develop the topic Female's Conditions and Women's Health. Written and oral individual accounts as well as stories constructed in "group meetings" were treated by the gender perspective. The dynamics has facilitated relationships and self-knowledge, making it possible for day-by-day situations to emerge. The reflection between what is lived and what is theoretical has allowed the visibility of women's insertion in the public and private sectors as well as created situations for the construction of concepts.

KEY WORDS: health education, psychodrama, women's health, social conditions

\section{PSICODRAMA COMO ESTRATEGIA PEDAGÓGICA: VIVENCIAS EN LA ENSEÑANZA DE PRE-GRADO EN EL ÁREA DE SALUD DE LA MUJER}

A partir de una discusión del Grupo de Estudios sobre Salud de la Mujer - GEM, el psicodrama ha sido utilizado como estrategia de pedagogía para desarrollar el tema Condición Femenina y Salud de la Mujer. Declaraciones individuales, orales y escritas, e historias construidas en la "vivencia grupal", fueron tratados por la perspectiva del género. La dinámica está facilitando la relación y el auto-conocimiento, posibilitando la aparición de situaciones del cotidiano. La reflexión entre lo vivido y lo teórico ha permitido la visibilidad de la inserción femenina en el espacio publico y privado y creado situaciones para la construcción de conceptos

TÉRMINOS CLAVES: educación en salud, psicodrama, salud de la mujer, condiciones sociales

\section{REFERÊNCIAS BIBLIOGRÁFICAS}

01. BRANDÃO, Z. (org.). A crise dos paradigmas e a educação. São Paulo: Cortez, 1996. (Coleções Questões de Nossa Época, v. 35).

02. BRASIL. Ministério da Saúde. Assistência integral à saúde da mulher: bases de ação programáticas. Brasília: Centro de Documentação do Ministério da Saúde, 1984. (Série B: Textos Básicos de Saúde, 6).

03. FREIRE, P. Educação e mudança. Rio de Janeiro: Paz e Terra, 1979. (Coleção Educação e Comunicação, v.1).

04. GARAVELLI, M.E. Psicodrama y gênero. In: CONGRESSO BRASILEIRO DE PSICODRAMA, 9. São Paulo, 1996. (mimeo).
05. GIFFIN, K. Transição de gênero: condição feminina na sociedade atual. (mimeo).

06. LOS RIOS, R.; GOMEZ, E. A mulher face à saúde e ao desenvolvimento: um enfoque alternativo. Brasília: OPAS, s/d.

07. MOSER, C.O. N.Planificación de género y desarrolo: teoría, práctica y capacitación. Lima: Red entre mujeres - Flora Tristán Ediciones, 1995.

08. ROMAÑA, M.A. Construção coletiva do conhecimento através do psicodrama. Campinas: Papirus, 1992.

09. SAFFIOTTI, H. O poder do macho. São Paulo: Moderna, 1987.

10. SANTOS, B.S. Um discurso sobre as ciências. 7. ed. São Paulo: Afrontamento, 1995.

Recebido em: 10.5.1999

Aprovado em: 21.3.2000 